\title{
New Horizons for Academic Libraries
}

More than 2,600 librarians and their friends gathered in Boston in November 1978 for a four-day conference on the occasion of ACRL's fortieth anniversary. This first national conference for academic librarians was not a time for retrospection; rather the conference theme, "New Horizons for Academic Libraries," provided a chance to look forward to the changes, opportunities, and challenges awaiting college, university, and research libraries in this last quarter of the twentieth century.

A group of distinguished educators and librarians presented a series of theme addresses in general sessions at the conference, each one addressing a specific aspect of this future. In this issue of College $b$ Research Libraries we are pleased to present seven of these papers.

Mary F. Berry opened the conference with her view of the road ahead for higher education in the United States and the role of the federal government in its support. Warren J. Haas succeeded her and presented his overview of the ways and means involved in the future of academic library management.

Joe B. Wyatt addressed the conference on the subject of technology and the library; and Barbara Evans Markuson summarized the contributions of networks to academic library change.

Richard W. Boss viewed a future for the academic library in which it serves as an information broker; and Jay K. Lucker discussed the future for library resources and their bibliographic control.

Millicent D. Abell concluded the theme sessions with her thoughts on the changing role of the academic librarian and the choice between "drift and mastery."

These papers present the speakers' views as seen from the vantage point of the autumn of 1978 . This was a time when the nation's librarians prepared through a series of state meetings for a White House Conference on Library and Information Services and when they were speaking of the need for and desirability of a national information policy. Several months earlier the Council on Library Resources had published its technical development plan for a national periodicals center; and only a few weeks before the meeting began several national groups had announced their support for a national library agency. Developments such as these served as major motifs in the speakers' comments.

As these speakers looked to the future, calling attention-as Barbara Markuson expressed it-to some of the cloudy issues on the academic library horizon, they enjoined librarians to control their environment rather than to be controlled by it; to transform themselves if they are to meet their obligations; to know there are risks in new endeavors and yet move ahead, or in currently popular words to be "born again." As Penny Abell concluded her paper, she stated the choice between drift and mastery should not be left to "a few articulate and powerful professional leaders-our stars." Rather the responsibility is for each of us. That choice must be "not in our stars, but in ourselves." 


\section{A Legacy Fulfilled... The United States Serial Set Complete \& Accessible}

The US Serial Set may well be the most valuable collection of Federal publications in existence. It is the oldest on-going series, and it is among the most varied and voluminous.

Dating back to 1789, the set encompasses an extremely broad range of subjects in its hundreds of thousands of titles. These were produced by $\mathrm{Con}$ gress, the executive departments and agencies, and certain non-governmental organizations. The statistical, narrative, and other research material-some 11 -million pages in all - is indispensable to histori$\mathrm{cal}$, genealogical, and legal work. It also is of fundamental importance to contemporary studies in the social, political, economic, and physical sciences.

The Serial Set is an unmatched public legacy of information. Yet through the years, indexing has been inadequate and few complete or partial collections have been available. The situation remained virtually unchanged until 1975, when Congressional Information Service, Inc. began to comprehensively index and micropublish the entire set. Now the work is nearly done.

Today, any library - new or old, depository or not - can ensure that the public it serves is given access to, and can benefit from, a great legacy of information.

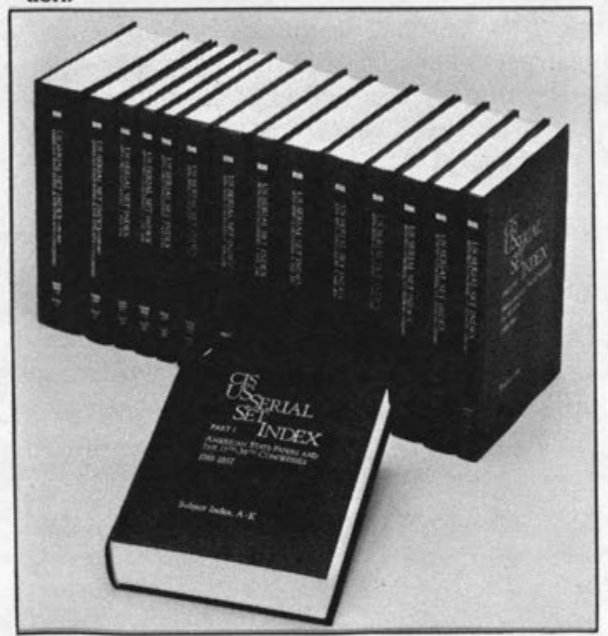

\section{CIS US Serial Set Index}

1789-1969 / 12 parts / 36 clothbound volumes / approx. 17,000 pages.

The sections in each part include: an Index of Subjects and Keywords, a Numerical List of Reports and Documents, a Schedule of Serial Volumes, and an Index of Names of Individuals cited in private relief and related actions. Bibliographic data in the index correlates to both the companion microfiche and the Serial Set in hardcopy form.

$\$ 360$ per part on standing order $/ \$ 400$ per part if purchased individually.

\section{CIS US Serial Set on Microfiche}

1789-1969 / 12 parts / approximately 115,000 archival quality microfiche reproducing the full texts of more than 330,000 publications contained in the first 14,500 bound volumes of the Serial Set.

Rigorously compiled to ensure inclusiveness and consistently organized for ease of access, the file meets or exceeds all applicable standards for the reproduction of archival material. Collections are shipped pre-collated and ready for use.

Available by Congress at list price, or at a discount in multi-Congress parts. A greater discount applies to orders for four or more parts (average price, $\$ 8,950)$. The complete collection is $\$ 107,445$.

A majority of the index and microfiche parts are available now at the prices originally announced in 1973. The entire project is scheduled for completion in Fall 1979, after which time prices are expected to increase substantially. Your inquiry should be addressed to:

Congressional Information Service, Inc.

7101 Wisconsin Avenue, Suite 900

Washington, D.C. 20014

Tel. 301/654-1550

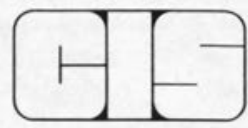

